\title{
A Horizontally Polarized Omnidirectional Antenna Using Stacked Curve Dipoles for DTV Reception
}

\author{
Chuwong Phongcharoenpanich, ${ }^{1}$ Weerayuth Polkaew, ${ }^{1}$ \\ Bancha Luadang, ${ }^{1}$ and Prayoot Akkaraekthalin ${ }^{2}$ \\ ${ }^{1}$ Faculty of Engineering, King Mongkut's Institute of Technology Ladkrabang, Bangkok 10520, Thailand \\ ${ }^{2}$ Faculty of Engineering, King Mongkut's University of Technology North Bangkok, Bangkok 10800, Thailand \\ Correspondence should be addressed to Chuwong Phongcharoenpanich; pchuwong@gmail.com
}

Received 31 August 2015; Revised 20 September 2015; Accepted 28 September 2015

Academic Editor: Xiulong Bao

Copyright (C) 2015 Chuwong Phongcharoenpanich et al. This is an open access article distributed under the Creative Commons Attribution License, which permits unrestricted use, distribution, and reproduction in any medium, provided the original work is properly cited.

\begin{abstract}
This paper presents an omnidirectional antenna using stacked curve dipoles radiating horizontal polarization for digital television (DTV) reception. The proposed antenna consists of stacked curve dipoles designed on brass sheet. The parametric study is carried out for various dimensions of curve dipoles to improve the impedance bandwidth. The results show good impedance matching for $\left|S_{11}\right|$ of less than $-10 \mathrm{~dB}$ along the frequency range from $404 \mathrm{MHz}$ to $871 \mathrm{MHz}$. The antenna gain is between $-10 \mathrm{dBi}$ and $0.67 \mathrm{dBi}$ along the frequency range from 470 to $862 \mathrm{MHz}$.
\end{abstract}

\section{Introduction}

Nowadays, television broadcasting services have switched from analog system to digital television (DTV) system. The DTV technology enables TV broadcasters to transmit high-definition (HD) image and audio signals $[1,2]$. The technology also makes the introduction of multimedia and interactive services possible. A second-generation terrestrial transmission system for digital television broadcasting, the so-called DVB-T2, is the most efficient DTV technology which is widely adopted in the European zone and operates on a frequency band of $470-862 \mathrm{MHz}$ [3-5]. In the DTV system, a receiving antenna is an essential device to receive signals from a transmitting antenna. In literature, a stuband capacitor-loaded folded dipole antenna has been proposed [1] for digital terrestrial TV reception. The numerical investigation clarified the effects of the stub and capacitor on bandwidth enhancement. In [2], a compact broadband microstrip-line-fed sleeve monopole antenna was presented. The design of meandering the monopole into a compact structure is applied for size reduction. A broadband printed dipole antenna with a step-shaped feed gap [3] has been proposed for $470-806 \mathrm{MHz}$ band. The wide operating band is formed by two excited resonant modes: one 0.5 -wavelength mode controlled by the antenna length $\mathrm{L}$ and one 1.0wavelength mode controlled by the total effective length (about $1.25 \mathrm{~L}$ ) of two radiating arms. A J-shaped monopole antenna array with matching circuits of a slot transmission line was considered in [4] for the purpose of compact size and thin structure. Reference [5] presented a miniaturized internal spiral multimode antenna for $470-862-\mathrm{MHz}$ band. This antenna uses seven spiral lines on the ground plane of microstrip line for multimode resonance. In combination with the multimode operational band, the entire DTV band of $470-862 \mathrm{MHz}$ is achieved. A dual-band 3D PIFA for DVB$\mathrm{T}(470-862 \mathrm{MHz})$ and WiMAX $(3300-3800 \mathrm{MHz})$ applications was presented [6]. This antenna is suitable to be integrated in a monitor. Additional resonant path was presented in this configuration. The thickness can be reduced by $43 \%$ (in terms of electrical length). An internal antenna was also developed for indoor reception of UHF terrestrial digital TV broadcasting system [7]. The new antenna can cover a bandwidth of larger than $60 \%$. It can resonate from $470 \mathrm{MHz}$ to higher than $900 \mathrm{MHz}$. A wideband microstrip slot antenna 


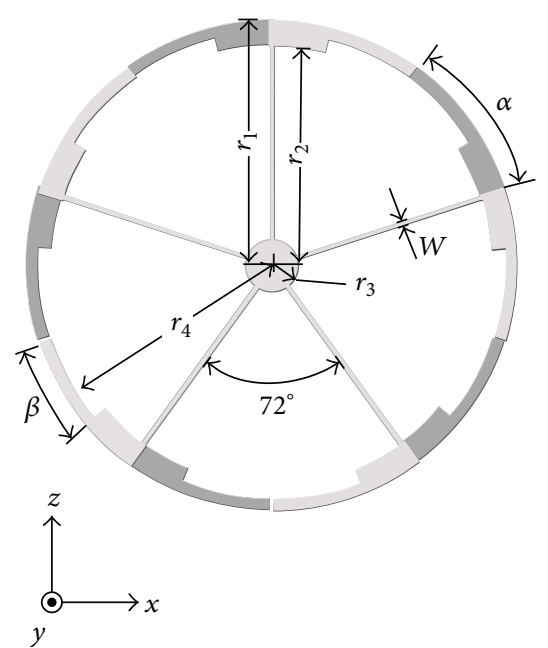

(a)

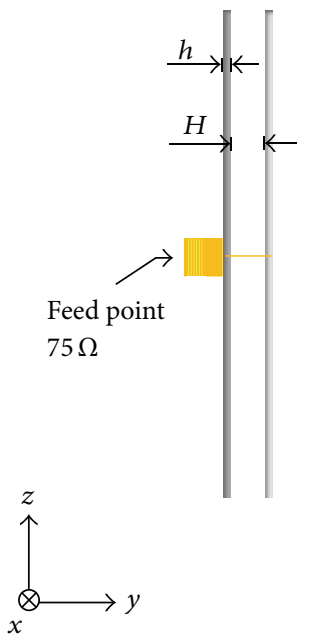

(b)

Figure 1: Configuration of the proposed antenna: (a) top view and (b) side view.

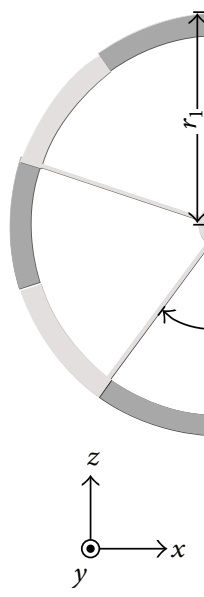

(a)
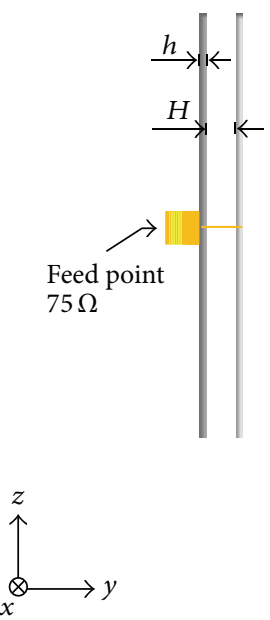

(b)

Figure 2: Configuration of the stacked curve dipoles (5 elements): (a) top view and (b) side view.

[8] was proposed for DTV ( $496 \mathrm{MHz}$ to $862 \mathrm{MHz}$ ) band along with fully planar frequency reconfigurable microstrip loop structure with MIMO implementation for wireless LTE compatibility. The PIN diode switches had been used as the switching element between the LTE bands 3 and 7 . Additionally, there are some researches about the antennas radiating horizontal polarization with omnidirectional pattern. A broadband vertically/horizontally dual-polarized omnidirectional antenna with high isolation was proposed [9]. The element for vertical polarization is a modified lowprofile monopole, whereas the element for horizontal polarization is a planar circular loop antenna that contains four arc dipoles. In [10], a new compact omnidirectional antenna with horizontal polarization was proposed. The antenna etched on two sides of a circular substrate is characterized with low profile and light weight. An ultrahigh frequency (UHF) low-profile antenna was proposed [11] based on the discone geometry with addition of a back cavity, a short-circuiting structure, and a two-plate top structure to achieve both low-profile and wideband characteristics. A novel wideband planar omnidirectional horizontally polarized antenna for 4G LTE wireless systems and networks was presented [12]. From the mentioned references, the research about the flat antenna radiating horizontally polarized omnidirectional pattern is necessary for the DTV reception that is suitable for installing on the mobile station or vehicular applications. This paper deals with the optimal design of a receiving antenna suitable for DTV reception. Generally, a receiving antenna for DVB-T2 system requires horizontal polarization with omnidirectional beam and wide impedance bandwidth. The proposed antenna uses stacked curve dipoles designed on brass sheet. The structure of the antenna yields horizontal polarization and omnidirectional pattern. The rest of the paper is organized as follows: Section 2 describes the initial 


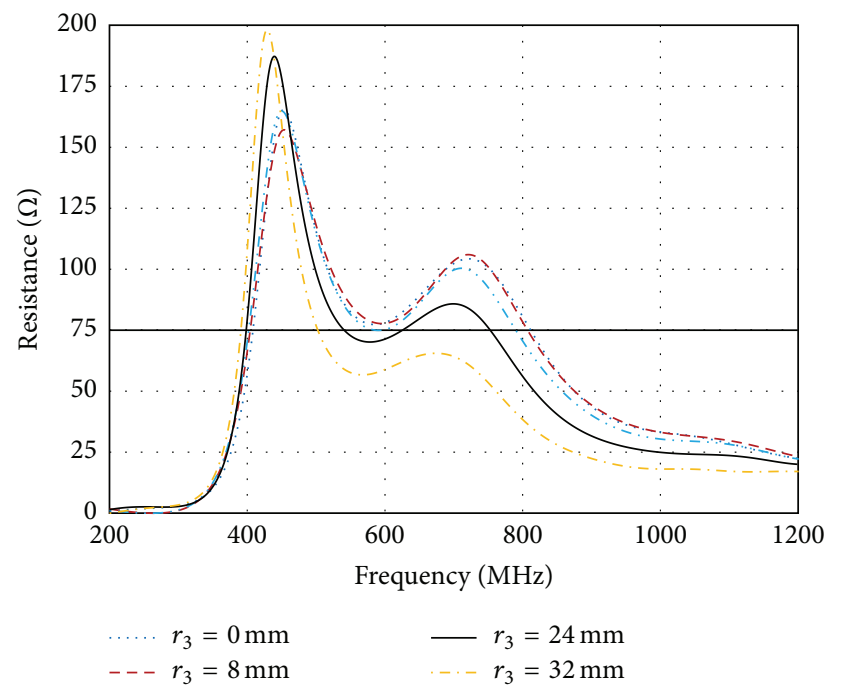

(a)

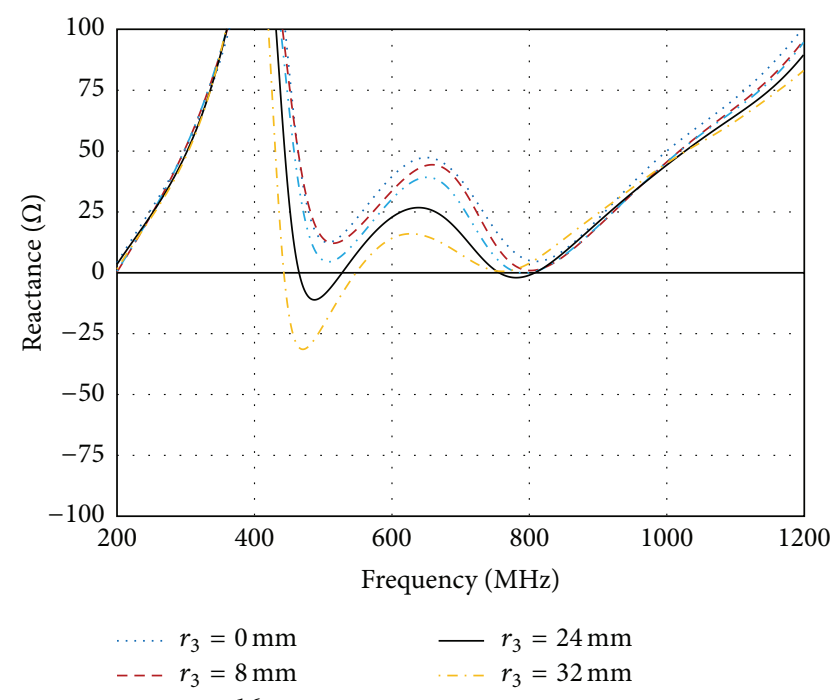

(b)

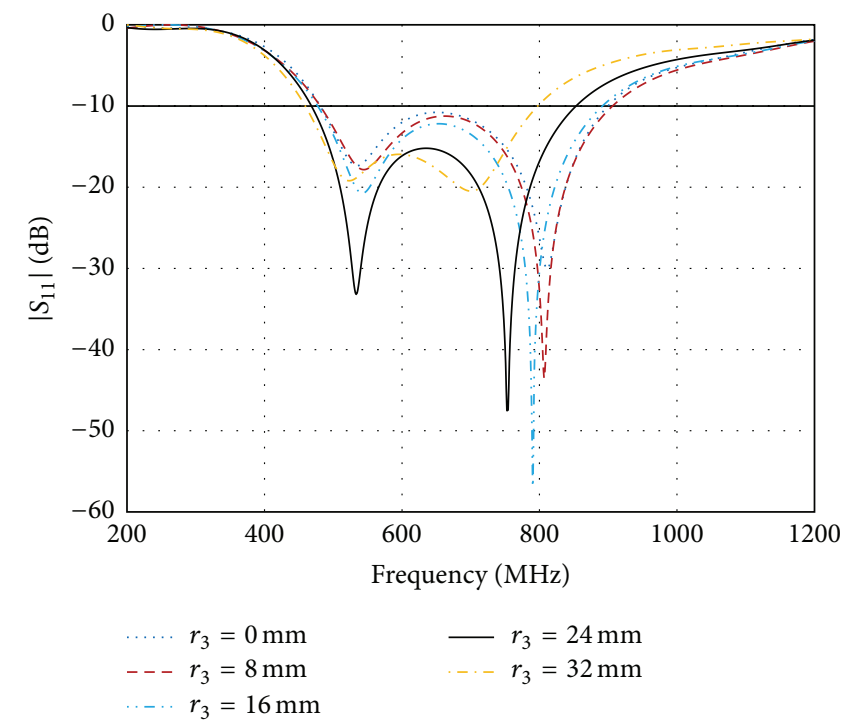

(c)

FIGURE 3: Simulated results for different radii of feeding structure $\left(r_{3}\right)$ of the initial antenna (5 elements): (a) input resistance, (b) input reactance, and (c) $\left|S_{11}\right|$.

design of antenna and subsequently the proposed antenna structure. Section 3 discusses simulated and measured results of the antenna. Section 4 is the concluding remarks.

\section{Antenna Structure}

This paper proposes a horizontally polarized antenna for DTV reception, as shown in Figure 1. The antenna structure is made from a thin brass sheet that consists of a number of curve dipoles. Each curve dipole is made of two overlapped arms located on two horizontal planes separated by an air gap. The structure of stacked curve dipoles is fed by a $75 \Omega$ coaxial transmission line. This proposed antenna uses a technique to enlarge dimension of stacked curve dipoles to improve the impedance bandwidth of antenna.
2.1. The Five-Element Stacked Curve Dipoles with Extended Feeding Structure (Initial Antenna). The initial antenna structure consists of the five elements of curve dipoles arranged to form the circular configuration. Two curved dipoles are stacked between each other in opposite directions with an air gap in between them. The feeding structure is located between the top and bottom layers as shown in Figure 2 . The antenna is designed to operate in the UHF band at the frequency range from $470 \mathrm{MHz}$ to $862 \mathrm{MHz}$. The radiation pattern is omnidirectional beam. The polarization is horizontal direction. The antenna structure is made of thin brass with thickness $h$ of $1 \mathrm{~mm}$ and the feeding point is at the middle between two layers. The CST Microwave Studio [13] is used as the simulation tool for this antenna investigation. 

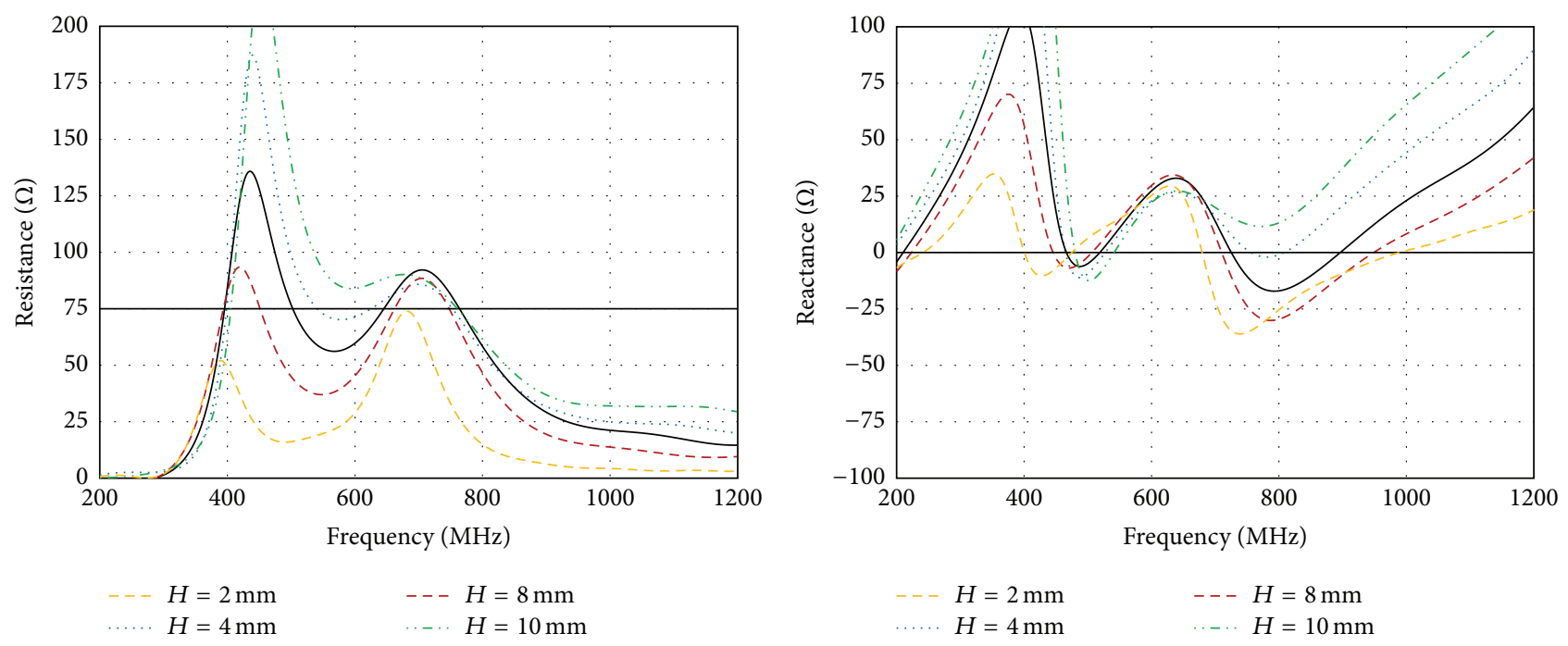

(a)

(b)

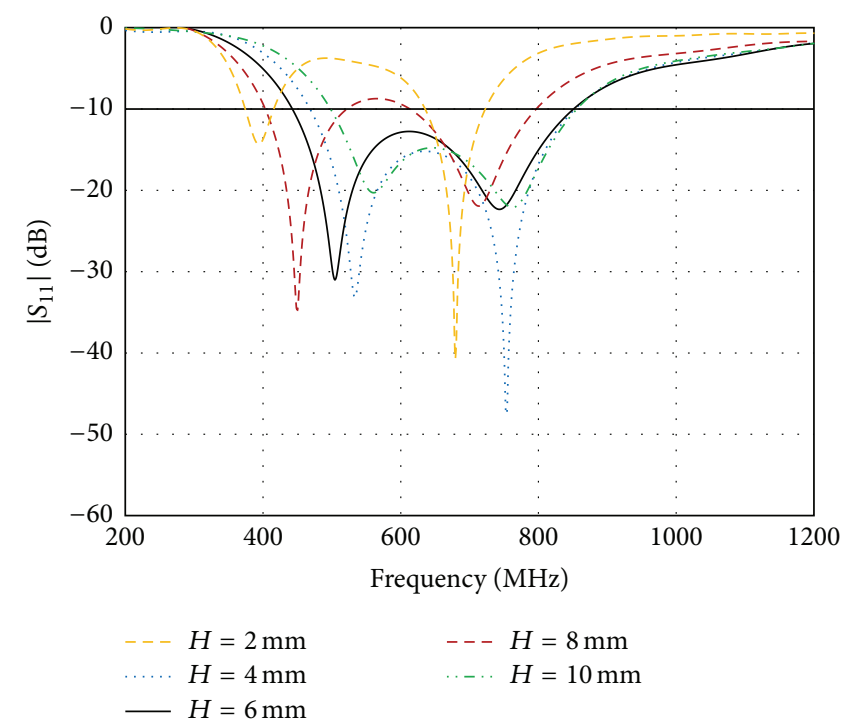

(c)

FIGURE 4: Simulated results for different spacing between stacked curve dipoles $(H)$ of the initial antenna (5 elements): (a) input resistance, (b) input reactance, and (c) $\left|S_{11}\right|$.

The initial antenna parameter is the outer radius of curve dipole $r_{1}$ with the dimension of the half wavelength of the center frequency $(666 \mathrm{MHz})$ of $22.5 \mathrm{~cm}$. The inner radius of curve dipole $r_{2}$ is $\lambda / 2.25$ or $20 \mathrm{~cm}$ in the initial stage. The width of dipole $\operatorname{arm}(W)$ is $2 \mathrm{~mm}$. The thickness of the brass sheet $h$ is $1 \mathrm{~mm}$. The suitable angle of curve dipole $\alpha$ is around $40^{\circ}$. The antenna parameters that will be varied to determine the suitable condition are the radius of feeding structure $r_{3}$ and spacing between stacked curve dipoles $H$. Subsequently, the outer and inner radii of curve dipole, $r_{1}$ and $r_{2}$, will be considered to study the effect on the resistance and reactance. The criteria of $\left|S_{11}\right|<-10 \mathrm{~dB}$ along the frequency range will be considered to cover the UHF band of the entire DTV system from $470 \mathrm{MHz}$ to $862 \mathrm{MHz}$. The radiation characteristics of omnidirectional beam will also be inspected.
From Figure 2, the antenna structure of 5 elements will be studied. The feeding structure is the circular geometry of radius of $r_{3}$. The antenna structure becomes completely overlapped between the curve dipoles in the opposite sides with the circular feeding structure.

From Figure 3, the radius of the feeding structure $r_{3}$ is varied. It is obvious that the radius of the feeding structure $r_{3}$ of $24 \mathrm{~mm}$ is the appropriated size. The reason is that the resistance is near $75 \Omega$ and the reactance approaches zero. However, the bandwidth becomes narrower when $r_{3}$ is wider because the electrical size of the antenna is reduced. The increase of $r_{3}$ has also influenced spacing between stacked curve dipoles $H$. Thus, the parameter $H$ will be varied again as shown in Figure 4.

When the radius of the feeding structure $r_{3}$ is $24 \mathrm{~mm}$, the spacing between stacked curve dipoles $H$ is varied. When 


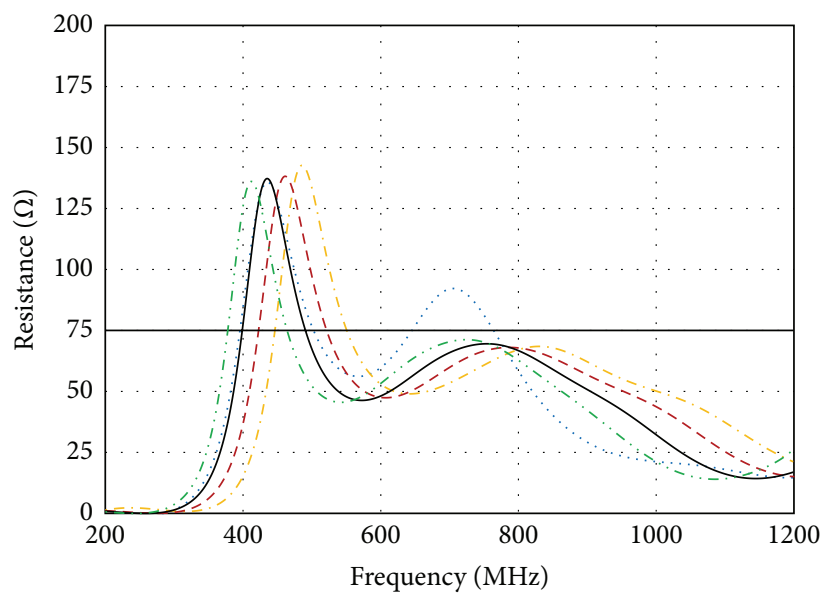

$\begin{aligned} \ldots . & r_{1}=150 \mathrm{~mm}, r_{2}=160 \mathrm{~mm} \\ --- & r_{1}=170 \mathrm{~mm}, r_{2}=160 \mathrm{~mm} \\ -- & r_{1}=180 \mathrm{~mm}, r_{2}=170 \mathrm{~mm}\end{aligned}$

(a)

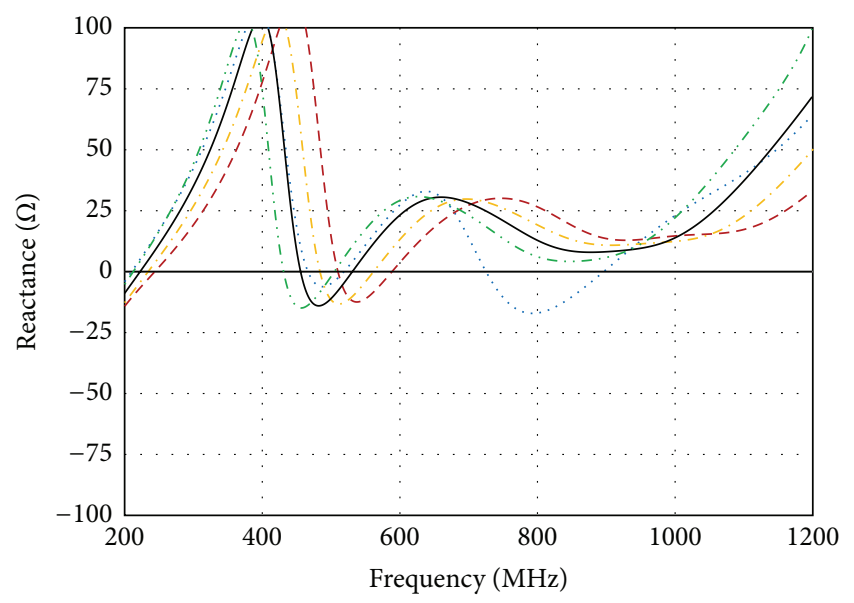

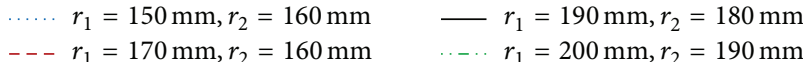

$r_{1}=180 \mathrm{~mm}, r_{2}=170 \mathrm{~mm}$

(b)

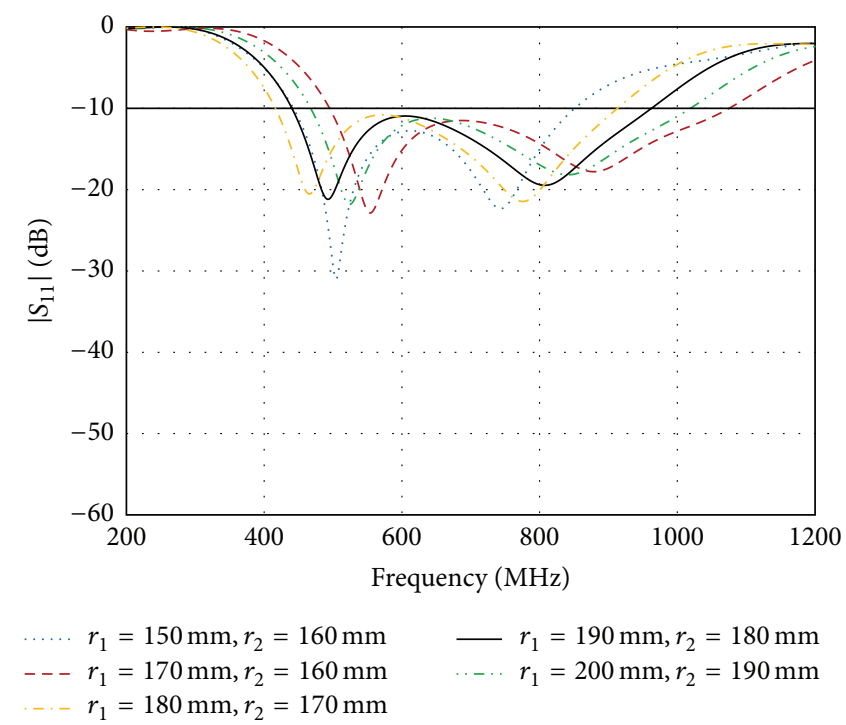

(c)

Figure 5: Simulated results for different outer and inner radii of curve dipoles $\left(r_{1}\right.$ and $\left.r_{2}\right)$ of the initial antenna (5 elements).

the spacing between the circular stacked curve dipoles is changed from $8 \mathrm{~mm}$ to $6 \mathrm{~mm}$, the bandwidth of the antenna can be enhanced as illustrated in Figure 4. However, it is found that the bandwidth cannot cover the frequency from $470 \mathrm{MHz}$ to $862 \mathrm{MHz}$. The area of the feeding structure will be influenced to the length of dipole or the outer radius of the curve dipole, $r_{1}$, and the inner radius of the curve dipole, $r_{2}$. When the length of dipole arm is shortened, the difference between $r_{1}$ and $r_{3}$ is decreased. These parameters will be adjusted to determine the appropriated parameters.

From Figure 5, the suitable parameters of the outer and inner radii of curve dipoles $\left(r_{1}\right.$ and $\left.r_{2}\right)$ are $190 \mathrm{~mm}$ and $180 \mathrm{~mm}$, respectively. The reason is that the resistance and reactance are close to $75 \Omega$ and $0 \Omega$, respectively, along the frequency range between $470 \mathrm{MHz}$ and $862 \mathrm{MHz}$. The $\left|S_{11}\right|$ is less than $-10 \mathrm{~dB}$ at this frequency band. However, the simulated results show that the initial antenna with five elements still has relatively high $\left|S_{11}\right|$ along the frequency band.

\subsection{The Five-Element Stacked Curve Dipoles with Extended} Feeding Structure and Additional Branch Curve (Final Proposed Antenna). From Figure 2, the initial antenna is started with the antenna consisting of 5 elements and area extension of the feeding point to improve the $\left|S_{11}\right|$. The additional branch curved to the curve dipole can improve the impedance characteristics. There are two parameters to be varied, that is, the radius of branch curve, $r_{4}$, and the angle of branch curve $\beta$. The CST Microwave Studio [13] is used as the simulation tool. Figure 6 shows the input impedance and $\left|S_{11}\right|$ of the antenna versus the frequency for different $r_{4}$ and $\beta$. From the simulated results, the antenna can 

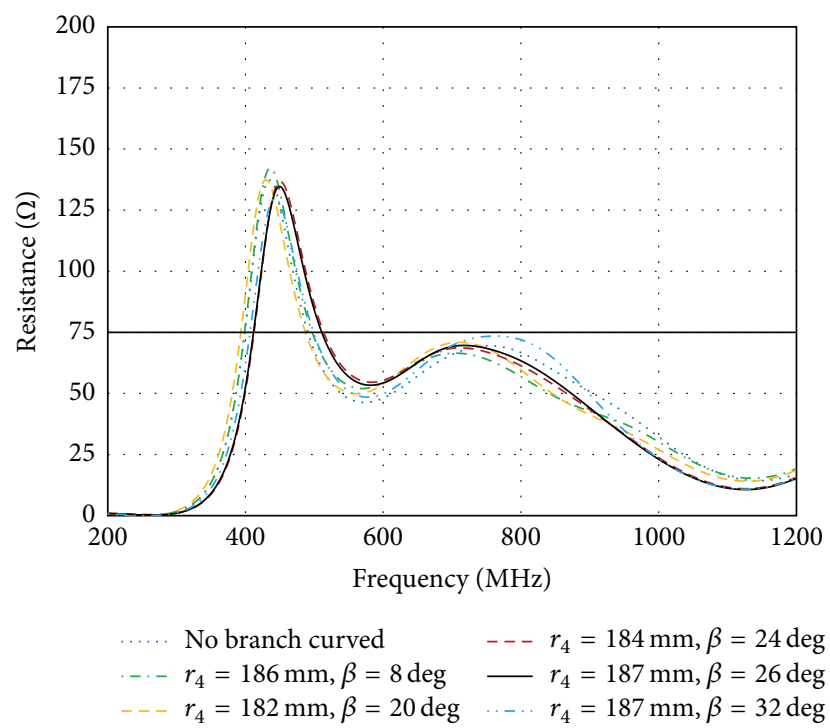

(a)

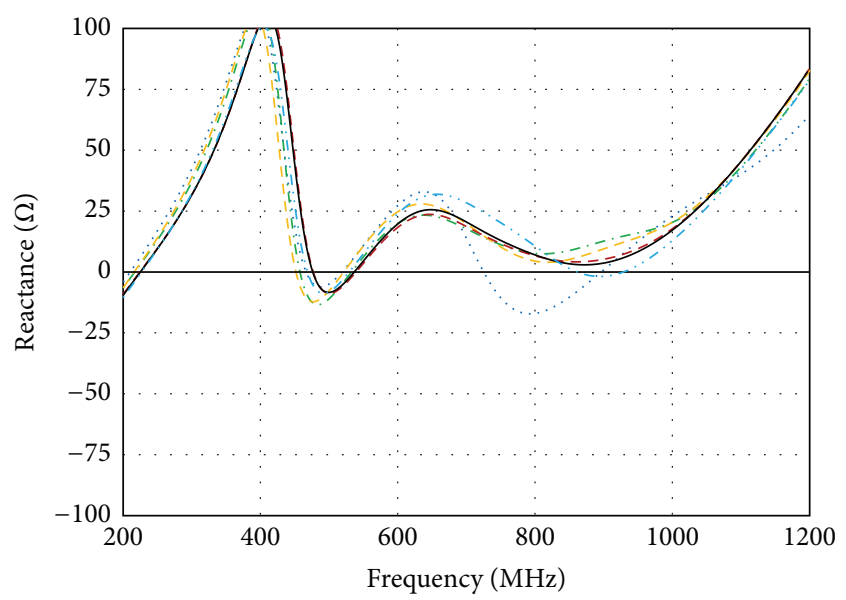

No branch curved $\quad---r_{4}=184 \mathrm{~mm}, \beta=24 \mathrm{deg}$ -. $r_{4}=186 \mathrm{~mm}, \beta=8 \mathrm{deg}-r_{4}=187 \mathrm{~mm}, \beta=26 \mathrm{deg}$ - $r_{4}=182 \mathrm{~mm}, \beta=20 \mathrm{deg} \cdots \cdots r_{4}=187 \mathrm{~mm}, \beta=32 \mathrm{deg}$

(b)

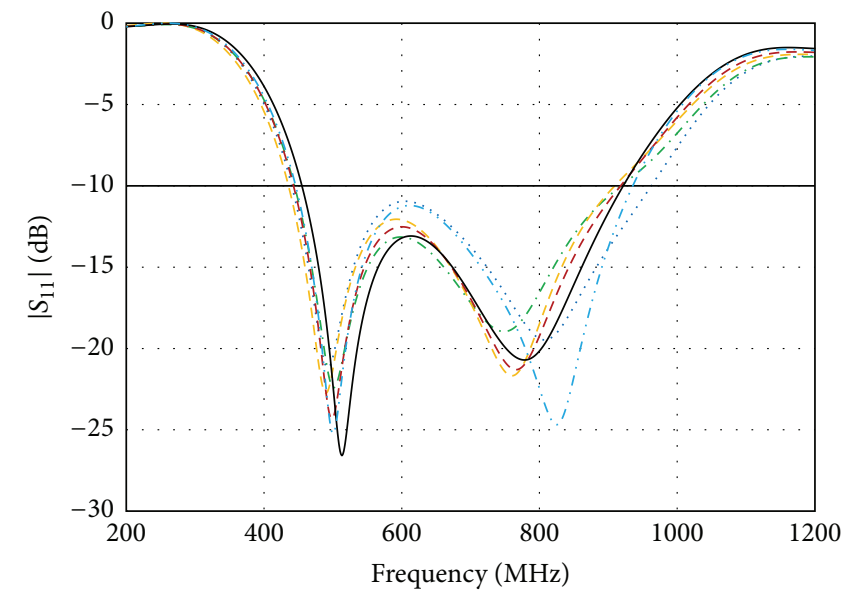

$$
\begin{aligned}
& \text { … No branch curved } \quad---r_{4}=184 \mathrm{~mm}, \beta=24 \mathrm{deg} \\
& \text {.. } r_{4}=186 \mathrm{~mm}, \beta=8 \mathrm{deg}-r_{4}=187 \mathrm{~mm}, \beta=26 \mathrm{deg} \\
& r_{4}=182 \mathrm{~mm}, \beta=20 \mathrm{deg} \cdots r_{4}=187 \mathrm{~mm}, \beta=32 \mathrm{deg}
\end{aligned}
$$

(c)

FiguRE 6: Simulated results for different radii of the branch curve $r_{4}$ and angles of the branch curve $\beta$ of the proposed antenna.

achieve the impedance close to $75+j 0 \Omega$ corresponding to $\left|S_{11}\right| \leq-10 \mathrm{~dB}$.

From the parametric study of the antenna with five elements and branch curve structure, the $\left|S_{11}\right|$ can be improved to cover the UHF range of the entire DTV system. The parameters of the antenna with five elements and branch curve structure are tabulated in Table 1.

\section{Simulated and Measured Results}

To validate the simulated results, the prototype antenna was fabricated as depicted in Figure 7. The measurement of $\left|S_{11}\right|$, radiation pattern, and gain are carried out. It is obvious that the prototype antenna possesses $\left|S_{11}\right| \leq-10 \mathrm{~dB}$ covering the frequency range between $404 \mathrm{MHz}$ and $871 \mathrm{MHz}$ (467 MHz bandwidth) as shown in Figure 8. Figure 9 shows
TABLE 1: Designed parameters of the proposed antenna.

\begin{tabular}{lcc}
\hline Parameter & Description & Size \\
\hline$r_{1}$ & Outer radius of curve dipole & $190 \mathrm{~mm}$ \\
$r_{2}$ & Inner radius of curve dipole & $180 \mathrm{~mm}$ \\
$W$ & Width of dipole arm & $2 \mathrm{~mm}$ \\
$H$ & Spacing between stacked curve dipoles & $6 \mathrm{~mm}$ \\
$h$ & Thickness of brass sheet & $1 \mathrm{~mm}$ \\
$\alpha$ & Angle of curve dipole & $37 \mathrm{deg}$ \\
$r_{3}$ & Radius of feeding structure & $24 \mathrm{~mm}$ \\
$r_{4}$ & Radius of branch curve & $186 \mathrm{~mm}$ \\
$\beta$ & Angle of branch curve & $24 \mathrm{deg}$ \\
\hline
\end{tabular}

the simulated and measured gains of the antenna. It is apparent that the measured maximum and minimum gains are $-10 \mathrm{dBi}$ and $0.67 \mathrm{dBi}$, respectively. 


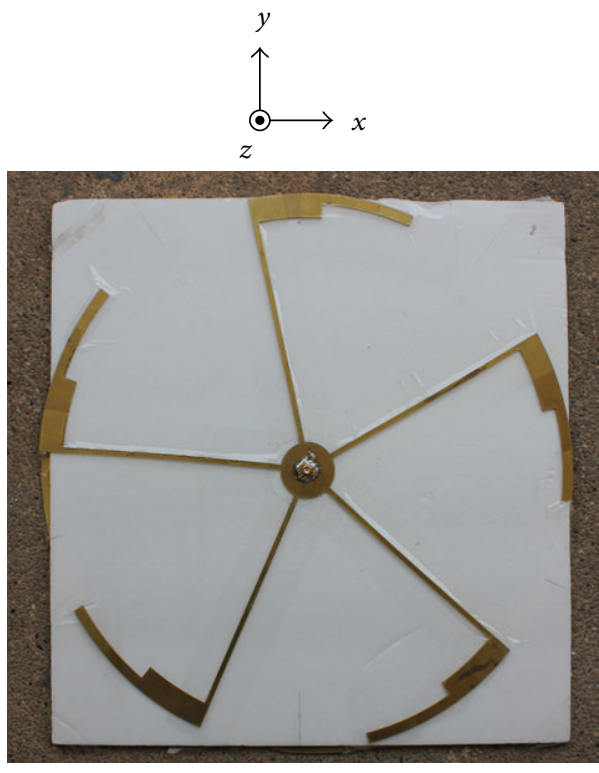

(a)

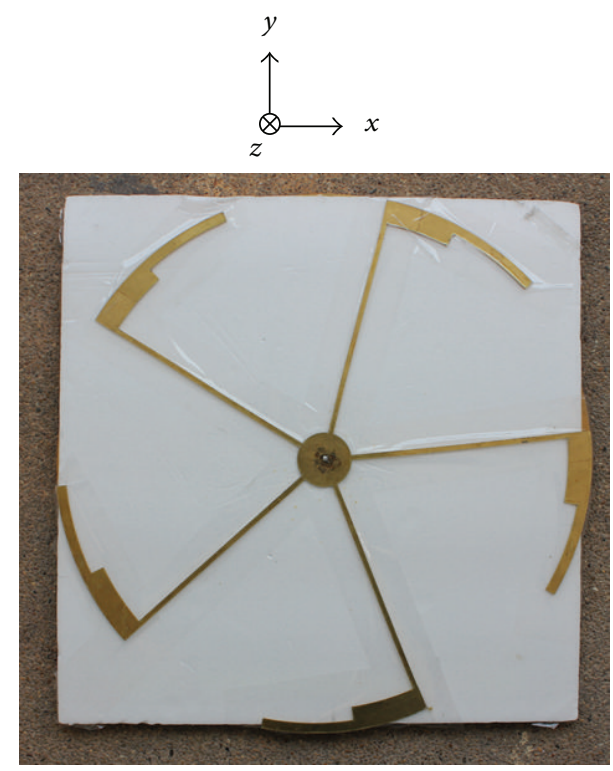

(b)

FIgURE 7: Photograph of the proposed prototype antenna: (a) top view and (b) bottom view.

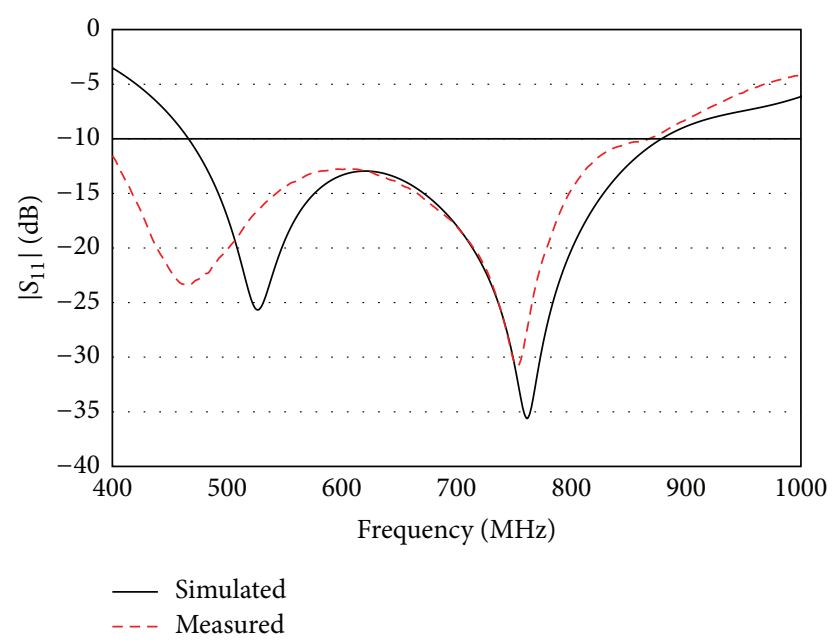

Figure 8: Simulated and measured $\left|S_{11}\right|$ versus frequency of the proposed antenna.

Figure 10 shows the comparison between the simulated and measured results of the radiation patterns at the frequency of $470 \mathrm{MHz}, 666 \mathrm{MHz}$, and $862 \mathrm{MHz}$. The prototype antenna radiates omnidirectional beam. The results include the radiation pattern in azimuth plane (vary $\phi$ and fix $\theta=$ $90^{\circ}$ ) and elevation plane (vary $\theta$ and fix $\phi=0^{\circ}$ ). It is noted that the cross-polarization levels in azimuth plane along the operating frequency band from simulation and measurement are lower than $-20 \mathrm{~dB}$ and $-15 \mathrm{~dB}$, respectively. In the elevation plane, the simulated and measured cross-polarization levels are lower than $-20 \mathrm{~dB}$, and $-9 \mathrm{~dB}$, respectively. The simulated half-power beamwidths in the elevation plane, at the frequencies of $470 \mathrm{MHz}, 666 \mathrm{MHz}$, and $862 \mathrm{MHz}$, are

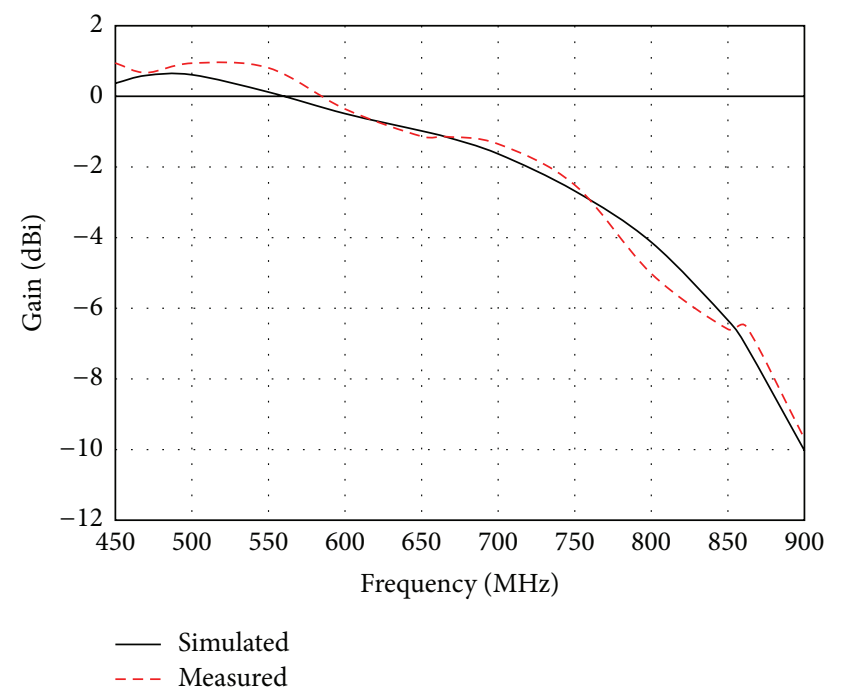

FIGURE 9: Simulated and measured gains of the proposed antenna.

$121.8^{\circ}, 140^{\circ}$, and $38.9^{\circ}$, whereas those of the measured results are $100^{\circ}, 70^{\circ}$, and $40^{\circ}$, respectively.

\section{Conclusion}

An omnidirectional antenna using stacked curve dipoles radiating horizontal polarization has been proposed for digital terrestrial TV reception. The measured results show that good impedance matching for $\left|S_{11}\right|$ less than $-10 \mathrm{~dB}$ covers the frequency range from $404 \mathrm{MHz}$ to $801 \mathrm{MHz}$. The antenna radiates omnidirectional patterns from $470 \mathrm{MHz}$ to $862 \mathrm{MHz}$. The measured gain of the proposed antenna 

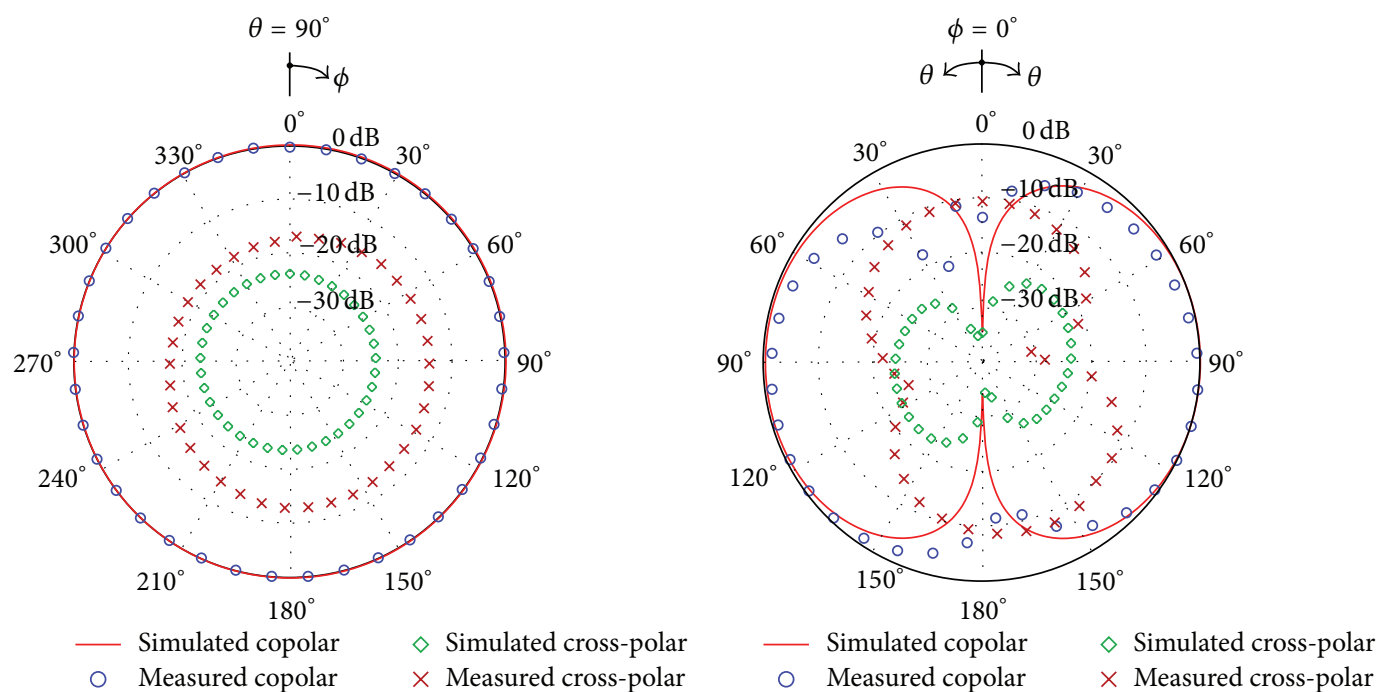

(a)

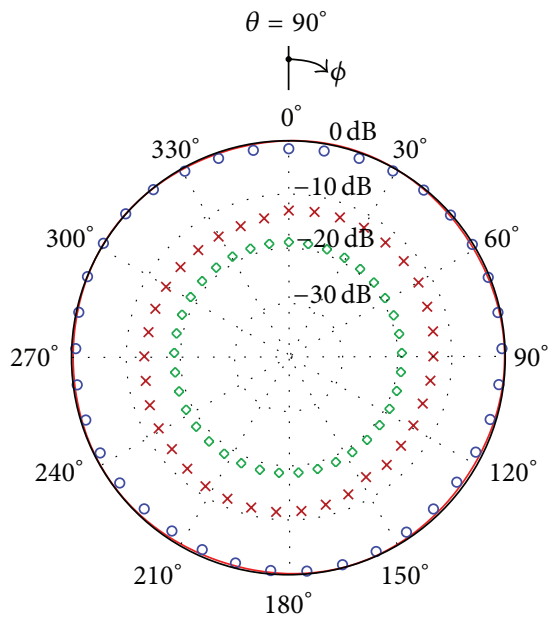

Simulated copolar
- Measured copolar

$\diamond$ Simulated cross-polar $\times$ Measured cross-polar

(b)
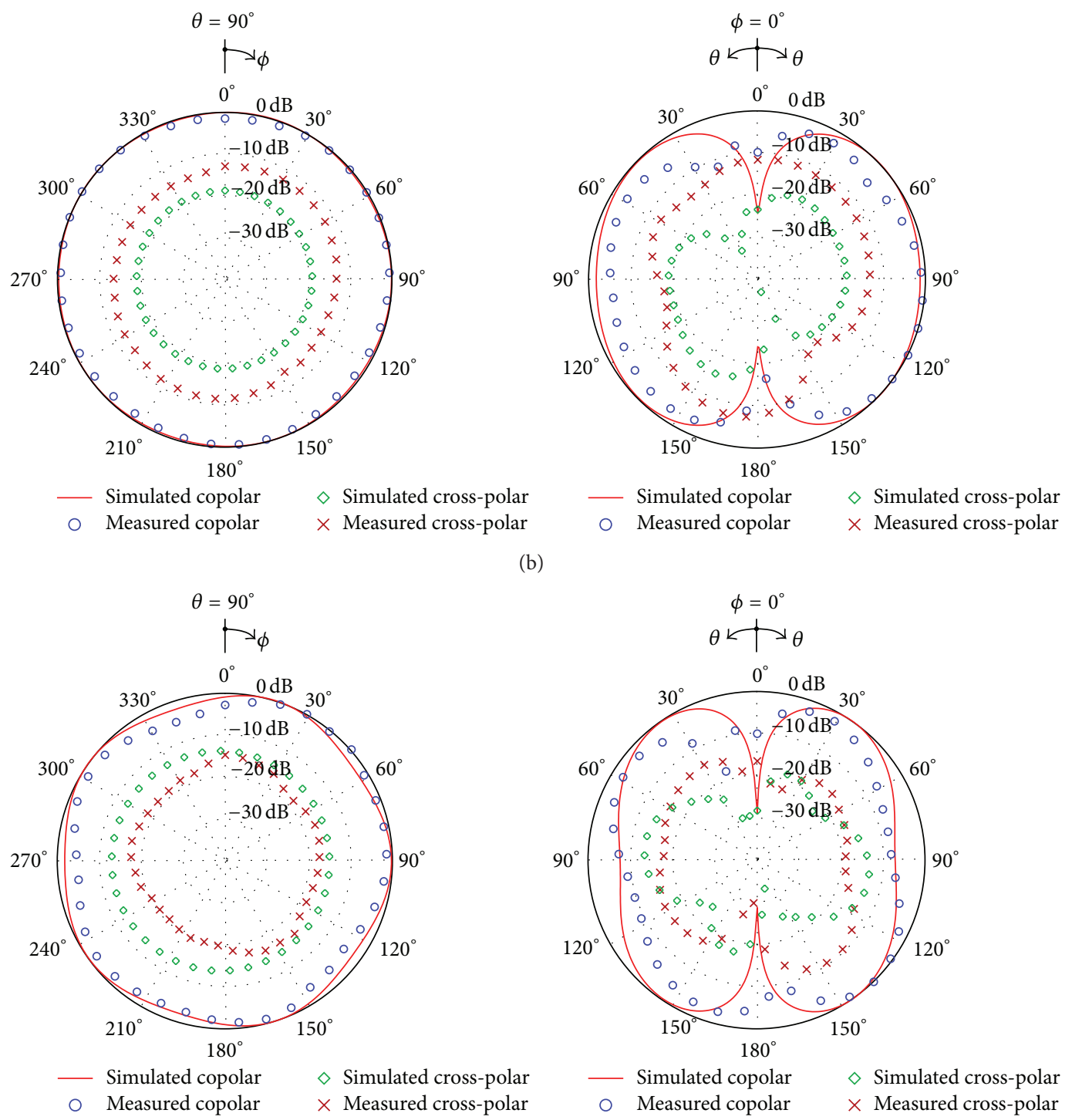

(b)

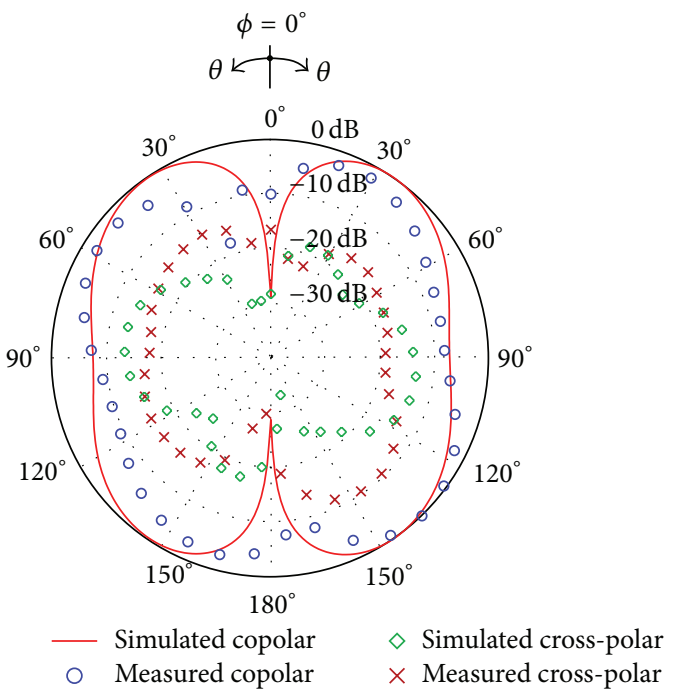

(c)

(c)

Figure 10: Simulated and measured radiation patterns (a) $470 \mathrm{MHz}$, (b) $666 \mathrm{MHz}$, and (c) $862 \mathrm{MHz}$. 
along the operating frequency from $470 \mathrm{MHz}$ to $862 \mathrm{MHz}$ is between $-10 \mathrm{dBi}$ and $0.67 \mathrm{dBi}$.

\section{Conflict of Interests}

The authors declare that there is no conflict of interests regarding the publication of this paper.

\section{Acknowledgment}

This work has been supported by the Thailand Research Fund through the TRF Senior Research Scholar Program under Grant no. RTA5780010.

\section{References}

[1] H. Iizuka, K. Sakakibara, and N. Kikuma, "Stub- and capacitorloaded folded dipole antenna for digital terrestrial TV reception," IEEE Transactions on Antennas and Propagation, vol. 56, no. 1, pp. 215-222, 2008.

[2] H.-D. Chen, "Compact broadband microstrip-line-fed sleeve monopole antenna for DTV application and ground plane effect," IEEE Antennas and Wireless Propagation Letters, vol. 7, pp. 497-500, 2008.

[3] Y.-W. Chi, K.-L. Wong, and S.-W. Su, "Broadband printed dipole antenna with a step-shaped feed gap for DTV signal reception," IEEE Transactions on Antennas and Propagation, vol. 55, no. 11, pp. 3353-3356, 2007.

[4] S. Kashihara and F. Kuroki, "J-shaped monopole antenna array as an antenna for terrestrial digital broadcasting at UHF band," in Proceedings of the IEEE MTT-S International Microwave Symposium (IMS '09), pp. 293-296, IEEE, Boston, Mass, USA, June 2009.

[5] D.-B. Lin, P.-C. Tsai, I.-T. Tang, and P.-S. Chen, "Spiral and multimode antenna miniaturization for DTV signal receptions," IEEE Antennas and Wireless Propagation Letters, vol. 9, pp. 902905, 2010.

[6] R. Caso, A. D’Alessandro, A. A. Serra, P. Nepa, and G. Manara, "An integrated dual-band PIFA for DVB-T and WiMAX applications," IEEE Antennas and Wireless Propagation Letters, vol. 10, pp. 1027-1030, 2011.

[7] M. Sanad and N. Hassan, "An internal EBG antenna for indoor reception of UHF terrestrial digital TV broadcasting," in Proceedings of the 10th Mediterranean Microwave Symposium (MMS '10), pp. 178-181, Guzelyurt, Turkey, August 2010.

[8] A. N. Kulkarni and S. K. Sharma, "Frequency reconfigurable microstrip loop antenna covering LTE bands with MIMO implementation and wideband microstrip slot antenna all for portable wireless DTV media player," IEEE Transactions on Antennas and Propagation, vol. 61, no. 2, pp. 964-968, 2013.

[9] X. Quan and R. Li, "A broadband dual-polarized omnidirectional antenna for base stations," IEEE Transactions on Antennas and Propagation, vol. 61, no. 2, pp. 943-947, 2013.

[10] C. Jiang, X.-W. Dai, and Y.-C. Jiao, "A novel compact horizontally polarized omni-directional antenna," in Proceedings of the International Symposium on Signals Systems and Electronics (ISSSE '10), vol. 1, pp. 1-3, IEEE, Nanjing, China, September 2010.

[11] A. Chen, T. Jiang, Z. Chen, and D. Su, "A novel low-profile wideband UHF antenna," Progress in Electromagnetics Research, vol. 121, pp. 75-88, 2011.
[12] Y. Yu, F. Jolani, and Z. Chen, "A wideband omnidirectional horizontally polarized antenna for 4G LTE applications," IEEE Antennas and Wireless Propagation Letters, vol. 12, pp. 686-689, 2013.

[13] CST-Microwave Studio, User's Manual, CST-Microwave Studio, 2006. 

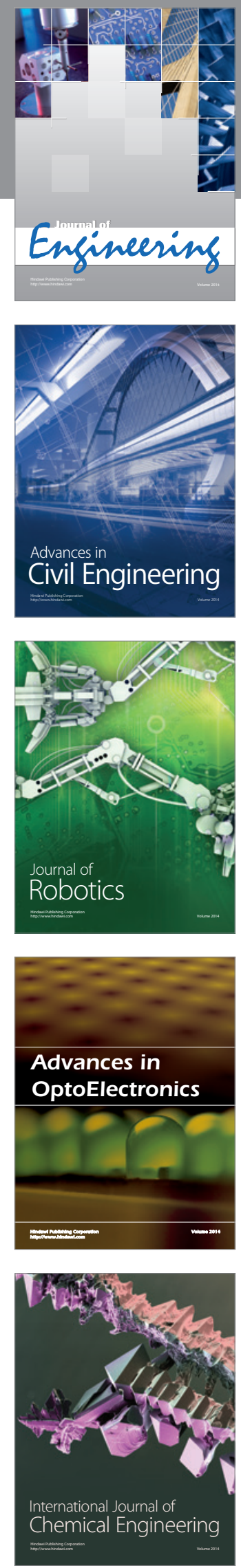

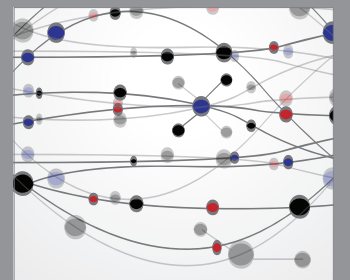

The Scientific World Journal
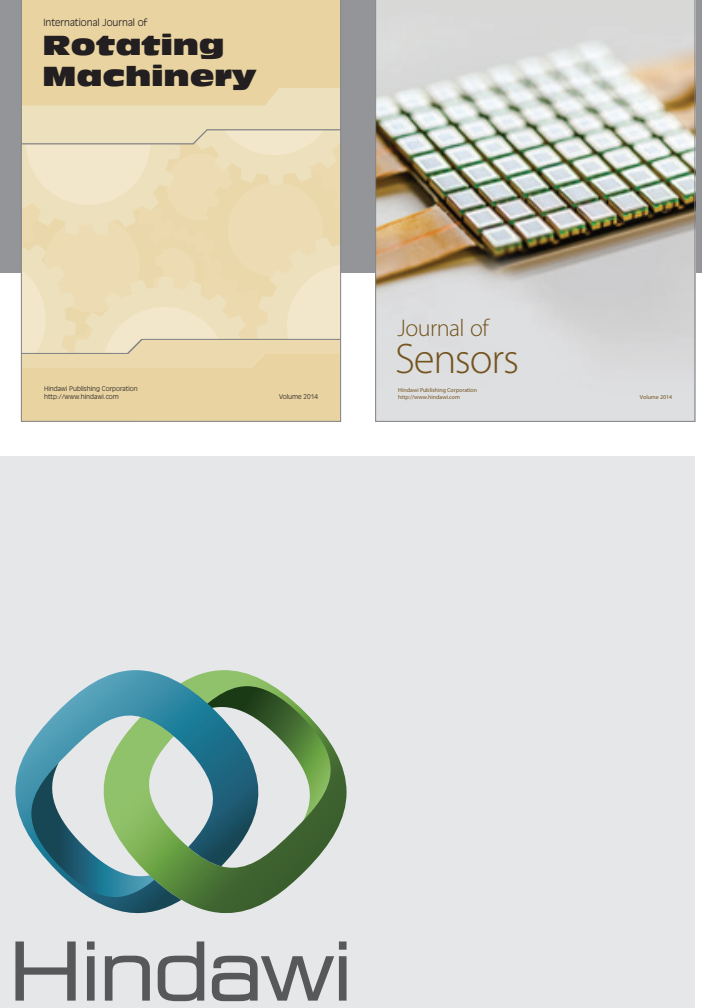

Submit your manuscripts at http://www.hindawi.com
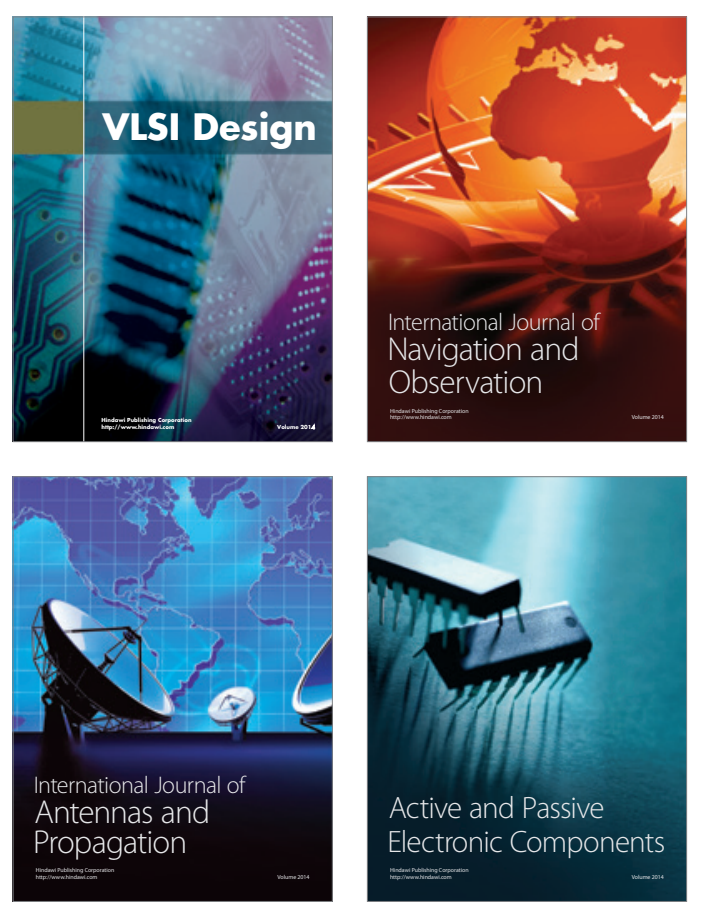
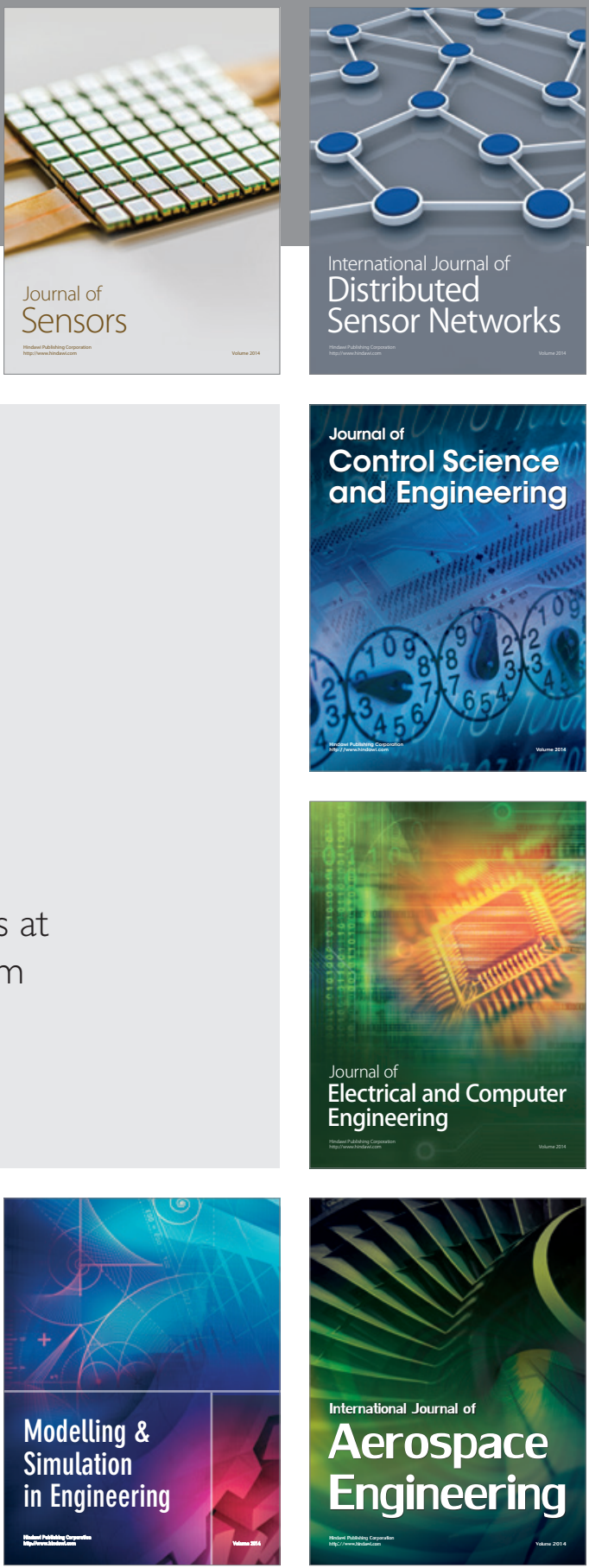

Journal of

Control Science

and Engineering
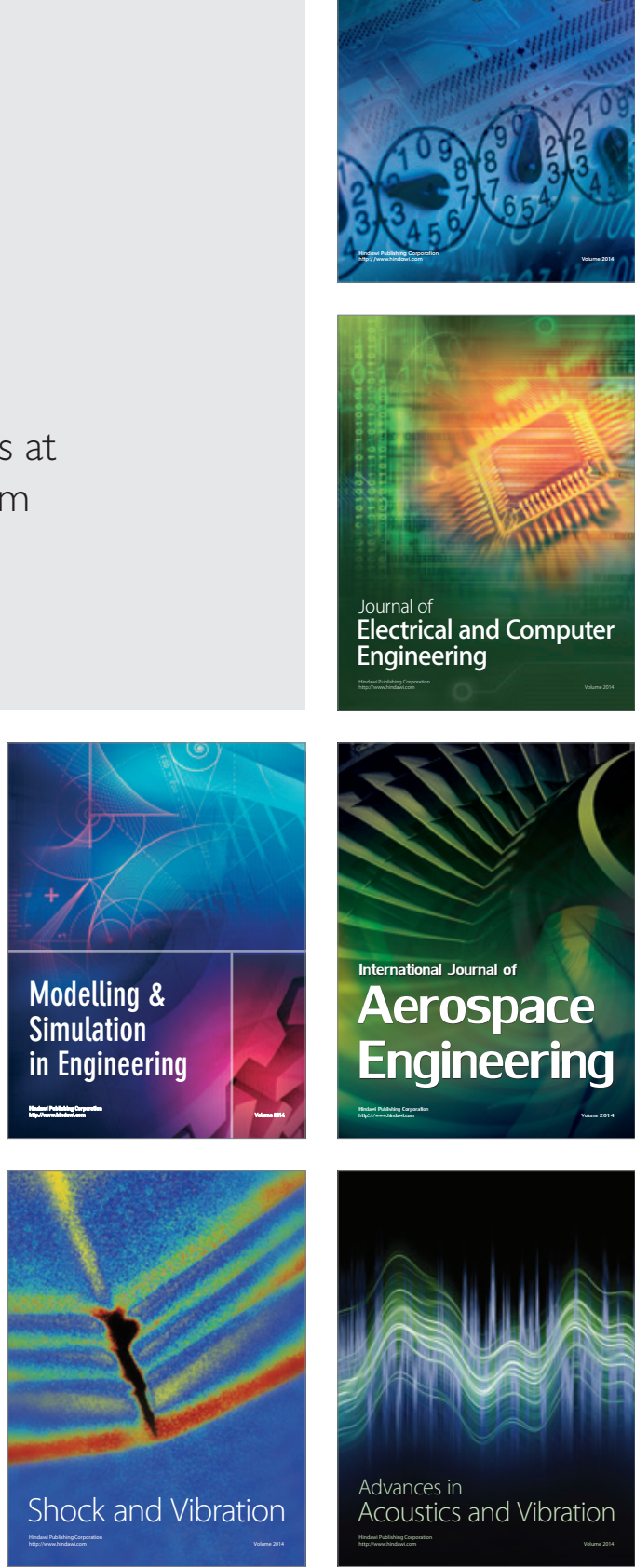